\title{
Construction Siding Subcontractor Installer Killed when Oversized Scaffolding Platform Destabilized and Telescopic Forklift Overturned
}

\section{CASE SUMMARY}

On Monday, June 15, 2015, two siding subcontract installers were standing on a 4 foot by 16 foot platform suspended 40 feet in the air, installing exterior insulation on the north wall of a newly constructed aircraft hangar. The platform was secured to the forks of a rough terrain telescopic forklift truck. At approximately 11:30 am, they signaled for the foreman, who was operating the forklift, to lower the platform. The foreman tilted the frame of the platform in order to avoid scraping the wall of the building during the platform descent, and lost control of the lever handle. The tilt became more pronounced and the weight of the 40 foot extended platform caused the forklift to turn over onto its left side slamming the platform onto the concrete ground below, killing the 23-year-old siding installer victim, and injuring the second siding installer. A laborer witness also performing

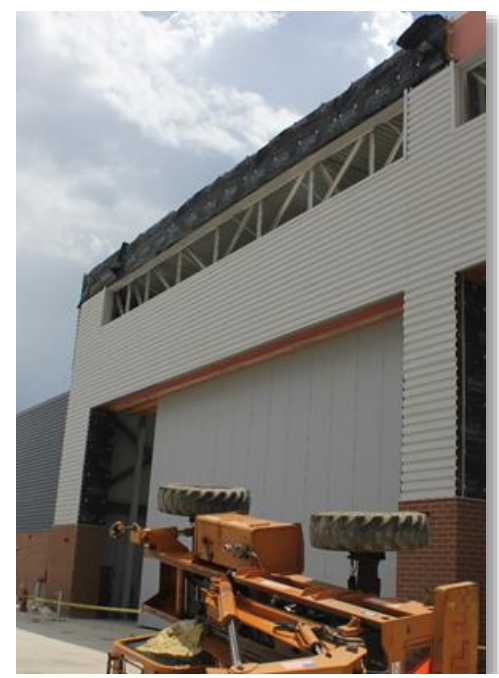

Figure 1. Telescopic forklift overturned at jobsite. work at the site called Emergency Medical Services (EMS). EMS arrived within four minutes. The victim was pronounced dead at the scene while the second injured siding installer was airlifted to a major trauma center for treatment.

\section{Recommendations for prevention:}

- Employers should provide appropriate siding equipment on the job site and ensure all employees are trained to operate the siding equipment.

- When lift equipment is required to elevate siding installers, choose only equipment specifically designated by the manufacturer for that purpose.

- Avoid tilting a forklift truck when the platform is elevated.

- When using a forklift approved by the manufacturer for personnel lifting, the width of a scaffolding platform should not exceed the width of the forklift wheel base. 


\section{EMPLOYER}

The employer was a roofing, siding and sheet metal sub-contractor located out of state with 5090 employees. The business opened on 6/13/1994. The company was employed by the on-site general contractor to install siding on an aircraft hangar.

\section{SAFETY AND TRAINING PROGRAMS}

The employer administered written safety programs to employees and provided evidence of occasional pre-shift safety talks at other jobsites but none for this jobsite. Fall protection training was the only documented training. Proof of rough terrain forklift truck training was provided but was dated after the incident occurred.

\section{VICTIM}

The victim was a 23-year-old, who had completed most of his high school education but was not a high school graduate. He had been previously employed with the company for 2 years, was rehired upon returning to the area, and had been employed for 2 weeks.

\section{INCIDENT SCENE}
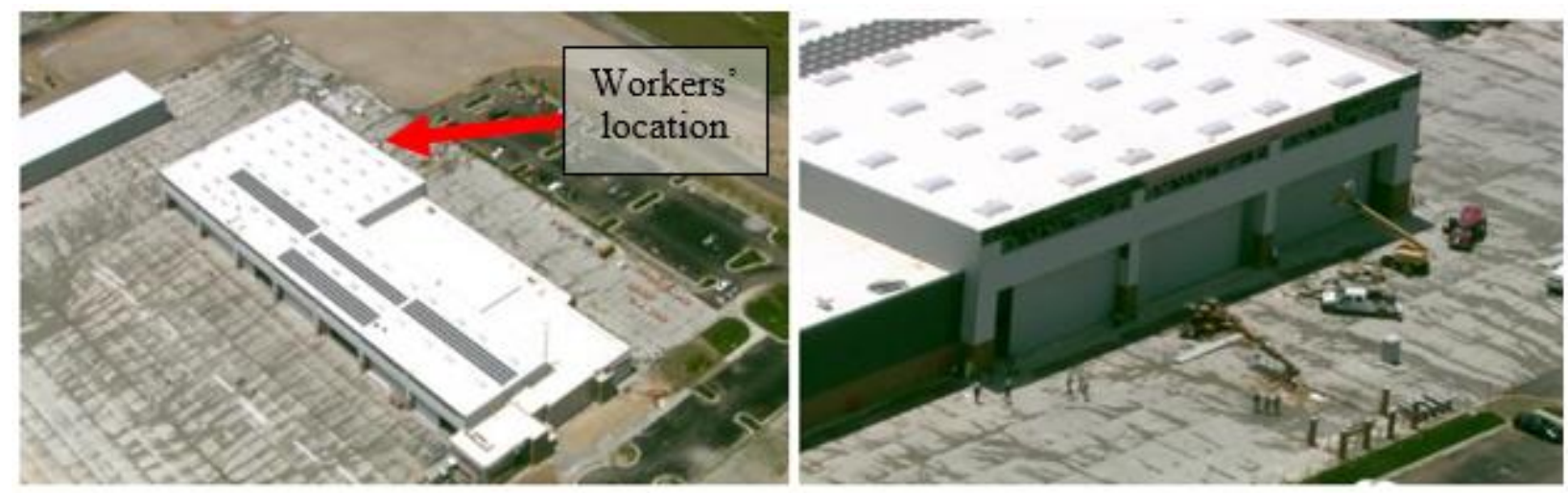

Figure 2. Aircraft hangar where the incident occurred.

The incident scene was a concrete parking lot where an aircraft hangar was under construction. The siding installers were installing insulation on the north wall of the building (figure 2) at the time of the incident, at an elevation of approximately 40 feet. 


\section{EQUIPMENT}

${ }_{1}$ A telescopic forklift, or telehandler, is similar in function and design to a standard forklift, but has the added versatility of upward and forward movement, reaching places that a conventional forklift cannot. These types of lifts are often used for placing loads on rooftops and hard-to-reach places.

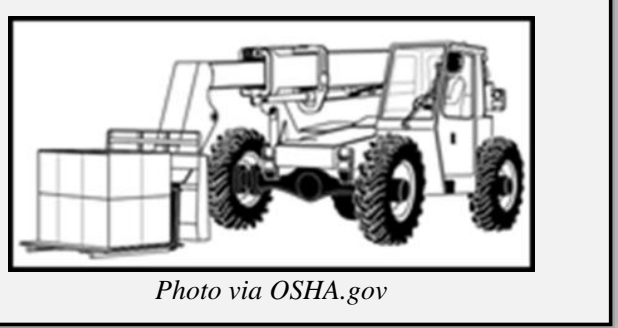

The equipment at the job site was a Lull model $844 \mathrm{C}$ rough-terrain telescopic forklift 1 with a wheelbase width of 8 feet and a load capacity of 8000 pounds (Figure 3A). The operator's manual warned that this equipment should only be used for material handling, and should never be used to lift personnel. This forklift model was not factory equipped with stabilizers to prevent it from tipping over.
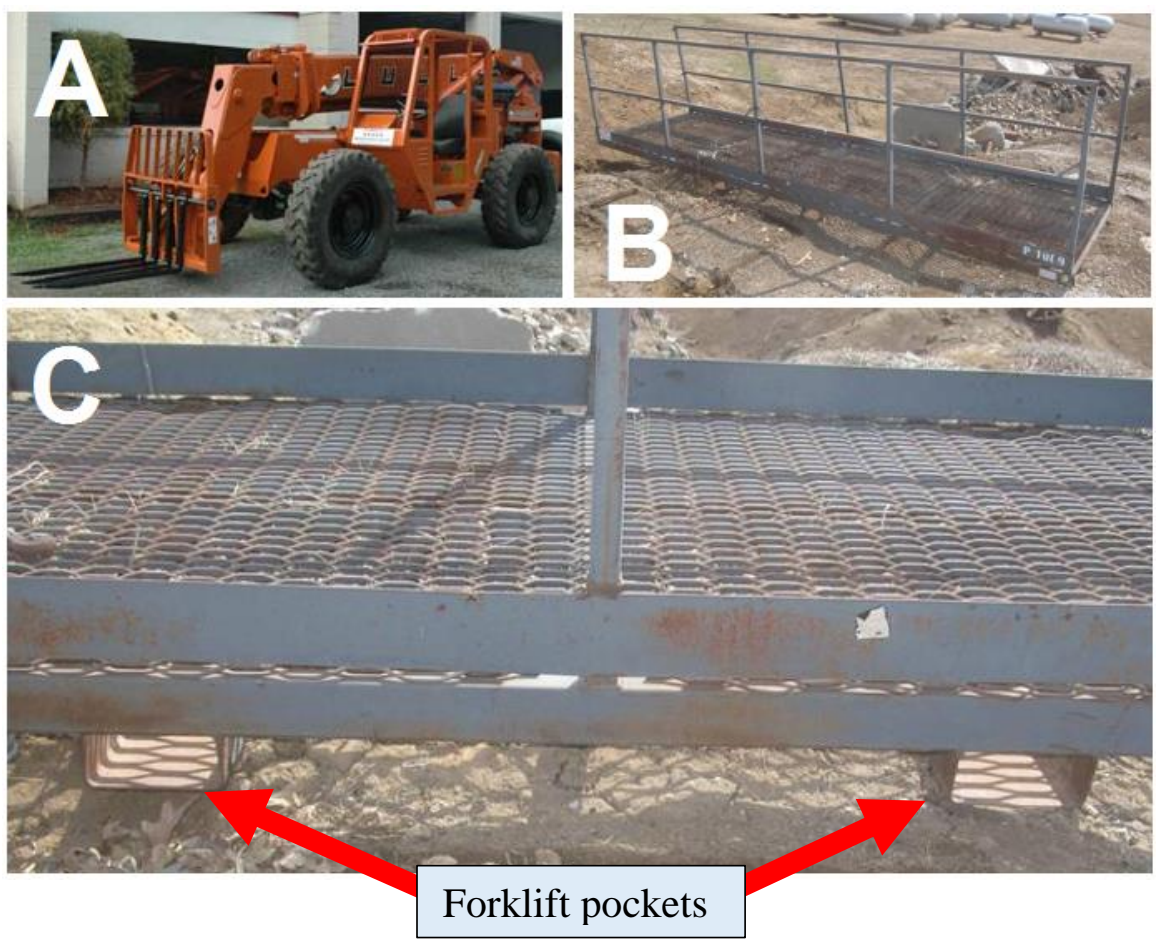

Figure 3. A) Stock image of a Lull $884 \mathrm{C}$ rough-terrain telescopic forklift. B) Stock image of an Arrow brand platform, model 90WP48192. C) Forklift pockets shown on actual platform.

Arrow brand man platform model 90WP48-192 was used as an attachment to the forks at the end of the forklift boom. This platform was constructed of steel and measured 4 feet by 16 feet, with 43 inch high side walls spanning the length of the platform and no end walls (Figure 3B). Additionally, there were forklift pockets located on both the middle of the long side and on the short ends of the platform to support scaffold platforms (Figure 3C). 


\section{WEATHER}

June 15, 2015, had temperatures ranging from 77 to 91 degrees Fahrenheit. The temperature was approximately $87^{\circ} \mathrm{F}$ with cloudy skies at the time of the incident. The humidity was $55 \%$, and the wind was blowing at 11.5 miles per hour from the west-southwest direction. Weather was not considered to be a factor in this fatality.

\section{INVESTIGATION}

On June 15, 2015, the Kentucky Labor Cabinet notified the Kentucky Fatality Assessment and Control Evaluation Program of a fatality involving an overturned rough-terrain telescopic forklift with a platform attached to the boom fork. An investigation was subsequently conducted.

An out-of-state roofing and sheet metal company had been hired as a sub-contractor to install insulation and siding on an aircraft hangar, which was nearing construction completion. A crew from the company, consisting of a foreman and two siding installers, arrived to side the hangar, and used a forklift to reach the approximately $40 \mathrm{ft}$. high area where the insulation was to be installed. To reach the top of the hangar, the foreman borrowed an 8 foot wide Lull brand roughterrain telescopic forklift and a $4 \mathrm{ft}$. by $4 \mathrm{ft}$. Arrow brand man platform from the general contractor (figure 3). This forklift type is designed to handle materials and factory warning on the forklifts says that it is not designed to lift personnel.

The foreman placed the forks in the slots on the Arrow platform and reinforced the securement with slings. The two siding installers then climbed onto the platform, secured their fall protection, and waited as the foreman lifted them approximately 40 feet into the air adjacent to the building.

At 11:25 am the employees signaled to the foreman that they were ready to come down. Concerned that the platform may scrape the side of the building during descent, the foreman used the forklift's chassis tilt function to tilt the platform to the left away from the side of the building. The foreman stated that when he tilted the frame of the

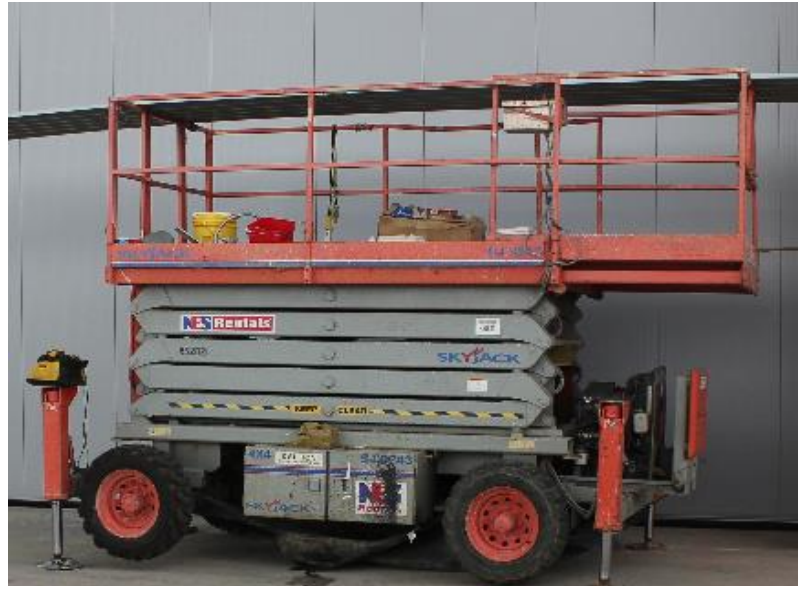

Figure 4. Skyjack SJ8243 Scissor lift which was located on the construction work site that would have been appropriate for lifting the personnel. This lift had a maximum height of 43 feet. forklift, he lost control of the tilt and in doing so, the tilt continued to increase. As the tilt increased, the weight of the extended platform caused the forklift to lose its equilibrium and overturn onto its left side, slamming the platform onto the concrete below. Upon impact, the sling used to secure the platform to the fork broke away and the platform's left-side guardrail broke off. While the foreman was able to avoid injury by jumping away, the two siding installers, who were secured to the platform, were thrown onto the concrete lot. A nearby laborer 
(employed by the general contractor) was walking to his van to get a drink of water when he witnessed the forklift overturning and immediately dialed 911 for assistance. The call was received at 11:30 am and Emergency Medical Services arrived at 11:34 am. One siding installer was pronounced dead at the scene at $12: 15 \mathrm{pm}$ while the other was airlifted to a major trauma center for treatment.

Located on the premises of the construction site was a Skyjack brand SJ8243 Scissor Lift which is specifically designed for the lifting of personnel (Figure 4). The Skyjack model had a maximum platform height of $43 \mathrm{ft}$., which would have been sufficient to safely access the working area. It is unclear why the Skyjack Scissor Lift was not used.
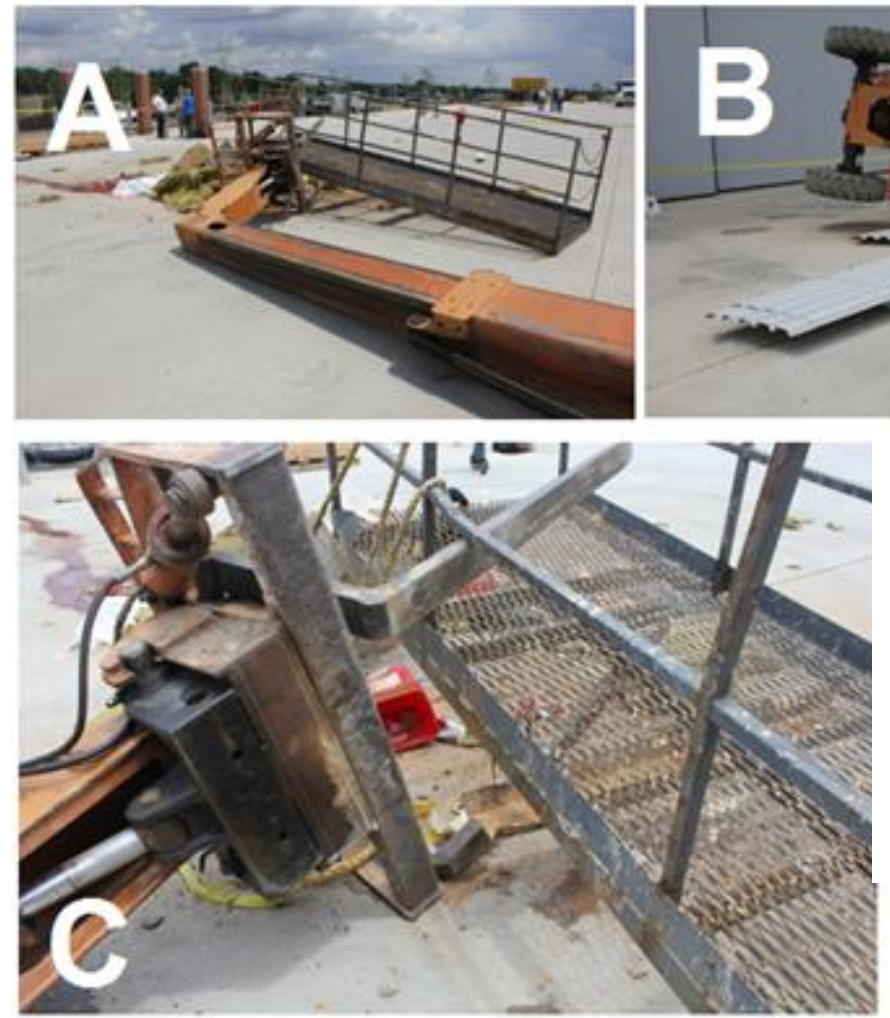

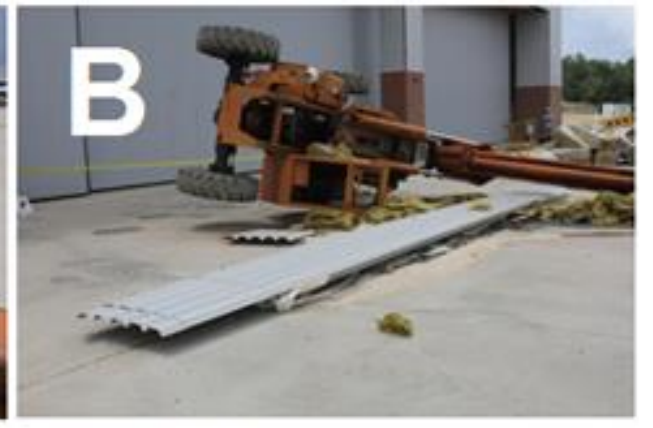

Figure 5. A) The boom and platform following impact. B) The overturned forklift following impact. C) The platform after it had broken off the slings and fork.

\section{CAUSE OF DEATH}

The cause of death was multiple blunt force injuries caused by a fall from approximately 40 feet.

\section{CONTRIBUTING FACTORS}

This investigation identified the following factors that may have contributed to the fatality:

- The rough terrain forklift truck was not designed to lift personnel

- The platform on the lift was too long, causing the forklift to become unstable 
- The operator tilted the lift while lowering the manned scaffold platform

- The employee was not trained to operate the lift

\section{RECOMMENDATIONS AND DISCUSSIONS}

Recommendation No. 1: Employers should provide appropriate siding equipment on the job site and ensure all employees are trained to operate siding equipment necessary to their jobs. ${ }^{1}$

In accordance with 19 CFR 1910.1783 employers must train employees before allowing them to operate equipment. The employees must demonstrate they are knowledgeable about the equipment and demonstrate safe operations of the equipment prior to operation. This training should include an overview of the operations manual to fully understand the limitations and uses of the equipment.

Recommendation No. 2: When lift equipment is required to elevate siding installers, choose only equipment specifically designated by the manufacturer for that purpose.

According to 29 CFR 1926.451(c)(2)(iv), front end loaders and other similar equipment, including rough terrain forklift trucks, should not be used to support scaffold platforms unless they have been specifically designed by the manufacturer to do so. ${ }^{2}$ The Lull operating manual stated not to use the rough terrain forklift truck as a personnel lift, as it was designed to handle material only.

The equipment used in this incident had been rented by the general contractor for use on the jobsite, and was loaned to the sub-contractor. It is unclear why the rough terrain forklift truck was chosen rather than the scissor lift which was also available to the sub-contractor.

Areal lift examples that would have been safer for this type of job (scissor lift and telescopic boom lift specified for lifting personnel):

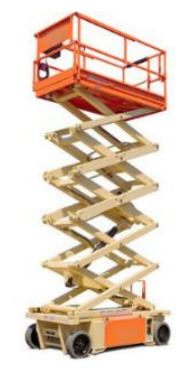

Scissor Lift

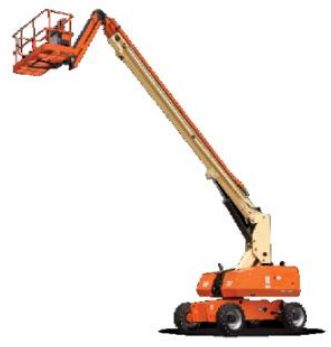

Telescopic Boom Lift

Recommendation No. 3: Avoid tilting a forklift truck when the platform is elevated.

The foreman tilted the chassis of the forklift to avoid scraping the siding of the building during the platform's descent. In doing so, he lost control of the lever, causing the platform and the 
forklift to lose balance and overturn. The Lull Operators Safety Manual states the following: "Always level machine before raising boom. Never tilt frame with the boom raised. Machine may tip and cause serious personal injury or death!" 3

Recommendation No. 4: When using a forklift approved by the manufacturer for personnel lifting, the width of a scaffolding platform should not exceed the width of the forklift wheel base.

The rough terrain forklift truck that was used had a chassis with two axles spanning $8 \mathrm{ft}$. wide. The platform was $4 \mathrm{ft}$. by $16 \mathrm{ft}$. This caused the platform to extend $4 \mathrm{ft}$. beyond the wheel base on each side of the forklift. According to the operator's manual and AMSE/ANSI B56.6 1992 safety standards, "A platform of the lift shall not have a greater width of the forklift."4

\section{OTHER RESOURCES}

Kentucky FACE Report: Roofing Foreman Dies from Telescopic Boom Lift Fall (08KY007). [http://www.mc.uky.edu/kiprc/projects/KOSHS/face/data/Reports/08KY007.pdf]

Kentucky FACE Report: 28-Year-Old Sound Technician Dies after Falling With Lift (03KY056) [http://www.mc.uky.edu/kiprc/projects/KOSHS/face/data/Reports/03KY056.pdf]

\section{KEYWORDS}

Platform

Forklift

Construction

Aerial boom

Scaffold lift

\section{REFERENCES}

${ }^{\text {I}}$ Training Requirements in OSHA Standards. OSHA.gov

${ }^{2} 29$ CFR 1926.451(c)(2)(iv) Standards for the Construction Industry. OSHA. Publication 2009 second edition.

${ }^{3}$ Machine Stability. Lull Operators and Safety Manual. Model 844C.

${ }^{4}$ ANSI/ITSDF B56.6-2005 Safety Standard for Rough Terrain Forklift Trucks. An American National Standard. Publication.

\section{PHOTO CREDIT}

The FACE Program would like to thank Kentucky OSH for providing scene photos. 


\section{ACKNOWLEDGEMENTS}

The Kentucky FACE program would like to thank KY OSH and the county coroner for their assistance with this report.

\section{PROGRAM FUNDING}

The Kentucky Fatality Assessment \& Control Evaluation Program (FACE) is funded by grant 2U60OH008483-11 from the National Institute for Occupational Safety and Health (NIOSH).

This case report was developed by the Kentucky Fatality Assessment and Control Evaluation (FACE) Program. Kentucky FACE is a NIOSH-funded occupational fatality surveillance program with the goal of preventing fatal work injuries by studying the worker, the work environment, and the role of management, engineering, and behavioral changes in preventing future injuries. The FACE Program is located in the Kentucky Injury Prevention and Research Center (KIPRC).

\section{Email: kyfaceprogram@uky.edu | Telephone: 859-257-5839 333 Waller Avenue Suite 242, Lexington, KY 40504}

Please take the time to complete our brief survey regarding this report:

(https://uky.azl.qualtrics.com/jfe/form/SV_aY9bX3mN3UzXqPr)

Electronic access to this full report can be found here:

(http://www.mc.uky.edu/kiprc/programs/face/files/15KY032.pdf)

Visit the KY FACE webpage for more reports like this:

(http://www.mc.uky.edu/kiprc/programs/face.html)

\section{FACE on Social Media:}

https://www.facebook.com/Kentucky-FACE-Program-

$\underline{134135740092906 / \text { ?view_public for }=134135740092906}$

http://www.twitter.com/KYFACEProgram 